\title{
Abolir o passado, reinventar a história: a escrita histórica de Hanfeizi na China do século III a.C.
}

\author{
Abolish the Past, Reinventing the History: the historical writing of \\ Hanfeizi in China, $3^{\text {rd }}$ century BC
}

\author{
André Bueno \\ orientalismo@gmail.com \\ Professor adjunto \\ Universidade Estadual do Rio de Janeiro \\ Rua São Francisco Xavier, 524/9023a - Maracanã \\ 20550-013 - Rio de Janeiro - RJ \\ Brasil
}

\begin{abstract}
Resumo
$\mathrm{Na}$ antiguidade, os intelectuais chineses acreditavam que a História continha todos os exemplos morais necessários para guiar a sociedade. Os pensadores deveriam buscar, no passado, as respostas para os desafios políticos, estratégicos e culturais. A História era, portanto, o caminho para a redenção moral. Todavia, no século III a.C., o pensador Hanfeizi, interessado em promover a teoria política da escola Legista, propôs que, sem abolir por completo o passado, seria impossível construir uma nova sociedade. Este artigo busca compreender no que consistia a proposta de Hanfeizi - abolir o passado, e reinventar a História - e os desdobramentos que ela teve para a sociedade e a historiografia chinesa.
\end{abstract}

\section{Palavras-chave}

Sinologia; China Antiga; Historiografia Chinesa.

\begin{abstract}
In ancient times, Chinese intellectuals believed that History contained all the necessary moral examples to guide society. Thinkers should seek, in the past, the answers to the political, strategic and cultural challenges. History was therefore the path to moral redemption. However, in the $3^{\text {rd }}$ century BC, the thinker Hanfeizi - who sought to promote the political theory of the Legalist school - proposed that without abolishing altogether the past, it would be impossible to build a new society. This article seeks to understand Hanfeizi's proposal of abolishing the past and reinventing history - and the consequences that it had for Chinese society and historiography.
\end{abstract}

Keywords

Sinology; Ancient China; Chinese Historiography.

Recebido em: 18/3/2015

Aprovado em: 10/7/2015 
No século $-3,{ }^{1}$ o reino de Qin 秦 ${ }^{2}$ dava pleno curso ao seu plano de unificar a China em um único Estado centralizado, baseado nas teorias defendidas pelos pensadores da Escola Legista (Fajia 法家). Várias foram as medidas tomadas nesse sentido: a classe nobre dos territórios conquistados teve suas terras confiscadas, e seu privilégios cassados; pesos, medidas, preços e moedas foram unificados, e uma fiscalização rigorosa foi estabelecida para garantir o funcionamento correto de mercados e tribunais. O governo nobiliárquico foi substituído por uma burocracia profissional, formada por funcionários treinados especialmente para lidar com questões jurídicas e administrativas (Sima Qian, Shiji 史記, cap. 5, "Qin Benji" 秦本紀). Todas essas medidas iam de encontro às mais arraigadas tradições da sociedade chinesa, causando insatisfações dos mais diversos gêneros.

Uma preocupação constante entre os teóricos legistas era, portanto, em como modificar os costumes do povo chinês, de maneira que a imposição do novo regime se consolidasse. Eles estavam cientes de enfrentar um desafio considerável: a cultura chinesa já se entendia milenar nesse período, com uma longa trajetória histórica que norteava a sua formação e lógica. Nesse sentido, pois, o pensador Hanfeizi 韓非子 (-280 -233) concebeu que a única forma de impor o novo sistema político e ideológico de Qin seria a abolição do passado. A história antiga não deveria mais servir de modelo para as gerações atuais; ela deveria ser restringida até ser esquecida, e seus modelos inspiradores deveriam ser apagados. Seu raciocínio parecia correto: afinal, para os historiadores 30 chineses desse período, a história significava o alicerce de sua civilização. Era nela que deveriam ser buscadas as inspirações, os modelos e respostas para os problemas que afligiam a sociedade. O estudo da história revelava as origens da cultura, dos ritos, de todas as práticas e costumes que determinavam a sua estrutura constituinte. Abolir a história, pois, implicava em desconectar-se com o passado, criando uma sociedade de novos hábitos e visões. Mas como fazê-lo?

A máquina administrativa de Qin fora capaz de atrair uma parcela significativa da população, interessada em ascender socialmente por meio do serviço público ou militar (YATES 2014, p. 141-155). No entanto, a escrita histórica permanecia a mesma, fomentando um conflito entre os intelectuais contra as novas propostas promovidas pelo governo. Hanfeizi percebeu, portanto, que era preciso desconstruir o sentido da escrita histórica chinesa, adaptando-a ao novo contexto ideológico.

Nesse artigo, pois, faremos uma análise da proposta de Hanfeizi para abolir o passado e reinventar a história, percorrendo o seguinte roteiro: inicialmente, faremos uma apresentação da escrita histórica chinesa tradicional, datada da época de Confúcio, e seus modelos fundamentais, de modo a compreendermos os conceitos, estilos e procedimentos com os quais Hanfeizi iria lidar; em um segundo momento, iremos nos deter especificamente em dois trechos de seus escritos, nos quais ele propõe a negação do passado, e no que se constitui a

${ }^{1}$ De acordo com uma convenção sinológica de uso corrente, as datas AEC são representadas pelo sinal "-", e as datas EC pelo sinal "+".

2 Ao longo do texto, a primeira aparição de um nome chinês será acompanhada de seu logograma. 
ideia de contradição-anacronismo; por fim, analisaremos os desdobramentos de sua proposta durante a dinastia Qin e no início do período Han, buscando compreender suas contribuições para a escrita da história chinesa.

\section{A crise ética na China Antiga e os modelos de história}

Para compreendermos a tradição histórica existente na época de Hanfeizi, precisamos retornar a um período anterior da história chinesa. Uma série de crises políticas e sociais afetava a estrutura do império chinês, durante a dinastia Zhou 周, em torno do século -6. Os Estados chineses, organizados de forma muito similar à estrutura feudal da Europa Medieval, combatiam uns aos outros, de modo incessante, numa infindável disputa pelo poder. Havia uma crise generalizada no meio social, representada pelo aumento da violência, da corrupção e da insegurança. Essa visão era compartilhada de modo geral por todos os autores e intelectuais desse período, que passaram a disputar, igualmente, a primazia de suas ideias como solução a crise iminente, constituindo um período histórico que ficou conhecido como "Época das Cem Escolas de Pensamento".

O primeiro desses pensadores, e mais destacado deles, foi Confúcio 孔夫子 (-551 a -479). Confúcio defendia que a crise social e institucional da sociedade chinesa, na época, era causada pela perda da Cultura e das Tradições ( Li 禮). Para ele, a solução seria promover um amplo programa educativo, capaz de tornar cada pessoa um elemento crítico e ativo na manutenção da sociedade. A proposta de Confúcio nos parece bastante moderna, mas tratava-se exatamente disso. Ele resgatou uma série de livros considerados clássicos e fundamentais para a Educação chinesa, e realizou uma vasta reedição e divulgação dos mesmos. Sua inspiração vinha diretamente do passado, e por isso, seu discurso baseava-se numa difusão da História como forma de redenção moral, através dos exemplos dos antigos. Ele mesmo afirmara: "não invento, apenas repasso" (Confúcio, Lunyu 論語, 7, 1, tradução minha) ${ }^{3}$ e "amo os antigos, e os imito" (Confúcio, Lunyu 論語, 7, 1, tradução minha). ${ }^{4}$ Sua frase mais famosa, porém, é: "Mestre é aquele que, por meio do antigo, descobre o novo" (Confúcio, Lunyu 論語, 2, 11, tradução minha). ${ }^{5}$ Por fim, ele afirmou: "A dinastia Zhou se espelhou nas duas anteriores; que civilização magnífica! Eu sigo Zhou" (Confúcio, Lunyu 論語, 3,14, tradução minha). ${ }^{6}$ Esse fragmento é fundamental para compreender o pensamento de Confúcio. Para ele, o exame do passado seria capaz de nos dar respostas para situações atuais - fosse pela aplicação de uma resposta similar àquela encontrada no passado, ou ainda, pela descoberta de uma nova resposta, ao constatar-se que um problema realmente não encontraria precedência na literatura histórica.

Por isso, Confúcio deu uma grande ênfase ao papel da história em seu projeto educacional. Todos os livros por ele resgatados tinham elementos historicizantes. O Tratado das Poesias (Shijing 詩經) preservara poemas

\footnotetext{
3 No original: "述而不作".

${ }^{4}$ No original: "信而好古".

${ }^{5}$ No original: "溫故而知新, 可以為師矣".

${ }^{6}$ No original: "周監於二代, 郁郁乎文哉! 吾從周".
} 
e músicas antigas, que ilustravam o imaginário da sociedade em tempos antigos; o Tratado das Mutações (Yijing 易經) explicava as antigas concepções científicas chinesas, e possuía ainda um caráter oracular; as Recordações da Cultura (Liji 禮記) apresentava uma vasta coleção de capítulos diversos, discutindo etiqueta, costumes, crenças, educação, música, tratando-se enfim de uma enciclopédia de cultura chinesa; e o Tratado da Música (Yuejing 樂經, hoje perdido) recolhera teorias e músicas capazes de representar e manifestar os sentimentos humanos na sociedade. Mas dois livros dessa coleção de seis clássicos eram, especificamente, de História. O Tratado dos Livros (Shujing 書 經) era uma coletânea de episódios e discursos das grandes personalidades do passado, demonstrando que os chineses já tinham o hábito de realizar registros históricos desde tempos imemoriais (ou ao menos, desde o séc.-12, quando iniciou a Dinastia Zhou); e as Primaveras e Outonos (Chunqiu 春秋) constituíam uma cronologia episódica dos tempos mais recentes, feita pelo próprio Confúcio, com os registros e arquivos mantidos pelo Estado de Lu 魯國, sua terra natal e lugar onde passou seus últimos anos.

Esses dois livros são bastante diferentes entre si. O Shujing é composto de capítulos longos, nos quais são apresentadas personagens centrais, e seus papéis no desenrolar de um evento. Breves informações biográficas formam a introdução de cada seção, apresentando o ator principal da narrativa. No seguir, acompanhamos seu discurso, ou a descrição do evento. O Shujing introduz a ideia da biografia exemplar, pela qual podemos tomar como modelo seus heróis 32 civilizadores. Um trecho do Shujing exemplifica o que queremos demonstrar:

Investigando a Antigüidade, verificamos que Di Yao se chamava Fang-
-Xun. Era reverente, esclarecido, instruído e atento, com naturalidade
e sem esforço. Era sinceramente cortês e capaz de toda e qualquer
complacência. A gloriosa influência dessas qualidades foi sentida nos
quatro quadrantes do território e alcançou o céu no alto e a terra aqui em
baixo. Distinguiu os capazes e virtuosos; depois, amou a todos aqueles
pertencentes às nove classes da sua parentela, que assim se tomou
harmoniosa. Regulamentou e refinou também o povo dos seus domínios,
que se tornou todo ele brilhantemente esclarecido. Por fim unificou e
harmonizou os inúmeros estados; assim se transformaram as populações
de cabelos pretos. E o resultado foi a concórdia universal (Confúcio,
Shujing, I, 1 'Canon de Yao' 堯典, tradução de Lin Yutang).

O modelo biográfico do Shujing deveria constituir um exemplo perfeito de analogia para a conduta moral e social, adequada de forma harmoniosa às leis da Natureza. A ideia de continuidade, perpetrada pelo sucesso em responder aos desafios do passado, embasava a necessidade de se ilustrar e se equivaler a esses modelos.

Mesmo assim, Confúcio nos revelou (ou investiu em) outra forma de escrita histórica, presente no Chunqiu. O texto desse livro é absolutamente seco, quase

\footnotetext{
7 Imperador Yao (Di Yao 帝堯), ou Fang Xun 放勳, soberano mítico do passado chinês, cujas datas se situariam entre -2358-2258.

${ }^{8}$ No original: "曰若稽古帝堯, 曰放勳, 欽、明、文、思、安安, 允恭克讓, 光被四表, 格于上下。克明俊德, 以親九族。 九族既睦, 平章百姓。百姓昭明, 協和萬邦。黎民於變時雍".
} 
fragmentário, apresentando uma data, os personagens e a descrição do evento. Segundo Liuxie 刘妿思 $(466+522)$ ， um dos primeiros especialistas em literatura chinesa, a explicação para essa diferença consistia na tipologia da redação histórica, presente desde a mais remota antiguidade chinesa:

O Quli diz; "os historiadores preparam seus pincéis para tomar notas", o que significa que "História" significa "anotar" - ou seja, historiadores são aqueles que, à direita ou à esquerda do soberano, anotam e recolhem seus registros. No Passado, os da esquerda recolhiam os fatos, os da direita as palavras. O clássico das Palavras é o Shangshu (Shujing), e o dos Fatos é o Chunqiu (Liuxie, Wenxin Diaolong 文心雕龍 16, tradução minha). ${ }^{9}$

Assim, a escrita das datas seria uma relação cronológica, baliza referencial para algum evento. No caso do Chunqiu, isso ficava ainda mais claro. Extraído diretamente dos anais da corte de Lu, ele nos parece incompreensível sem explicações adicionais. O que ocorre é que Confúcio redigira o texto de maneira criptográfica, justamente, para introduzir debates de caráter analógico aos episódios históricos. A escrita do Chunqiu é codificada: alguém que "morreu naturalmente" implica num personagem de vida exemplar, enquanto outro que "morreu de modo turbulento" deixa subentendido a acusação de um crime, um desregramento, ou simplesmente pode ser visto como um anti-modelo. As palavras usadas por Confúcio indicavam, de modo sutil ou direto, acusações ou louvações às figuras históricas, ou mesmo aos seus contemporâneos - motivo pelo qual ele foi constantemente perseguido durante um longo tempo de sua vida. Como comenta, novamente, Liuxie:

A partir do rei Ping, a dinastia começou a declinar, e não foi mais digna de figurar no Livro das Odes. Leis e normas se dispersaram e se enredaram, e os princípios eternos se perderam. O Mestre Confúcio lamentou profundamente que o soberano abandonara o Dao; desolado pela destruição de sua cultura, viveu retirado suspirando pela Fênix e vagou pelos caminhos clamando pela vinda do unicórnio. Mas então, se reuniu com o grande Mestre da Música para corrigir as poesias e os hinos; baseando-se na história de Lu escreveu o Chunqiu. Tratou dos enganos e dos erros para mostrar os avanços e retrocessos, e deu testemunho do que havia perdurado e do que havia perecido como conselho e advertência. Uma palavra de elogio valia mais que carruagens e vestidos cerimoniais; uma palavra de censura cortava mais profundamente que machados e facas. Seu significado profundo é obscuro e enigmático, mas o texto que o entrelaça é harmonioso e conciso. Qiuming, ${ }^{10}$ seu contemporâneo, chegou a compreender o mistério de suas palavras, partiu de sua raiz e alcançou os ramos. Assim criou o gênero dos comentários (o Zuozhuan) (Liuxie, Wenxin Diaolong 文心雕龍 16, tradução minha). ${ }^{11}$

Com o tempo, as explicações para as passagens foram se diluindo ou tornando-se confusas, o que levou posteriormente à redação de três livros

\footnotetext{
9 No original: “曲禮曰:史載筆。史者, 使也。執筆左右, 使之記也。古者左史記事者, 右史記言者。言經則《尚書》, 事經 則《春秋》也".

10 Zuo Qiuming 左丘明, autor do Comentário Zuo.

${ }^{11}$ No original: "自平王微弱, 政不及雅, 憲章散紊, 彝倫做㲔. 昔者夫子閔王道之缺, 傷斯文之墜, 靜居以歎鳳, 臨倠而泣 麟, 於是就太師以正《雅》、《頌》, 因魯史以修《春秋》。舉得失以表黜陟, 徵存亡以標勸戒; 褒見一字, 貴踰軒冕; 貶 在片言, 誅深斧鋮。然睿旨幽隱, 經文婉約, 丘明同時, 實得微言。乃原始要終, 創為傳體".
} 
auxiliares para explicar o Chunqiu: o Zuozhuan 左傳 (Comentário Zuo), o Guliangzhuan 穀梁傳 (Comentário Guliang) e o Gongyangzhuan 公羊傳 (Comentário Gongyang). Outros livros de comentários teriam existido, mas esses três foram os que mais se difundiram, sendo o Zuozhuan considerado, pela maior parte dos confucionistas, como o comentário "ideal" do Chunqiu, como citado por Liuxie.

Um fragmento pode nos ilustrar o teor do livro: "Inverno, 11a Lua, Lua Nova, o Duque de Song combateu Chu em Hong, o exército de Song foi derrotado" (Confúcio, Chunqiu, Livro Xigong 僖公, tradução minha). ${ }^{12}$ Notem, pois, o comentário árido de Confúcio: o Duque foi derrotado (grifo meu) pelo exército de Chu. Nada mais. Em sua época, provavelmente, a passagem era conhecida, e podia ser explicada, comentada e discutida. Todavia, o uso específico da palavra "derrota" tinha implicações diretas. Significava antes de tudo, por sua interpretação, que Song estaria errado em seus propósitos ou meios, e por essa razão, fora derrotado. Mas quais seriam? É o Zuozhuan que fornece uma longa historieta conexa para explicar a passagem. O duque Xian de Song contava com estrategistas hábeis, mas ele se supunha uma pessoa de inteligência privilegiada, moralmente superior e modesta - e por isso, não aceitou os conselhos de seus comandantes, terminado ferido na batalha. A palavra Sábio (Sheng 聖), em chinês, significa "Aquele que escuta". "Dar ouvidos", pois, seria uma atitude sensata, mas ele não o fez. Tudo isso se depreendia, assim, da análise de um único termo. Assim, o duque de Song se tornaria exemplo de fracasso moral e intelectual.

O uso cuidadoso das palavras, por parte de Confúcio, baseava-se na concepção do autor de uma profunda relação entre as terminologias e seus sentidos. Ele acreditava, de certa forma, que as analogias contidas nas palavras representavam de fato as ideias nelas contidas. Por isso mesmo Confúcio foi o primeiro defensor de uma Retificação dos Nomes (Zhengming 正名), tentando fazer com que o uso das palavras se adequasse intimamente ao contexto e ao sentido. Para ele, as palavras não deveriam guardar ambigüidades ou sentidos múltiplos:

Quando os nomes não são corretos, a linguagem fica sem sentido. Quando a linguagem fica sem sentido, nenhum assunto pode ser resolvido. Quando nenhum assunto pode ser resolvido, os ritos e a música cessam. Quando os ritos e a música cessam, punições e penalidades erram o alvo. Quando punições e penalidades erram o alvo, as pessoas não sabem onde estão. Por isso, aquilo que um educado concebe, ele tem de ser capaz de dizer; e aquilo que ele diz, ele tem de ser capaz de fazer. No que se refere à linguagem, um educado não deixa nada ao acaso (Confúcio, Lunyu 13, 3, tradução de Simon Leys). ${ }^{13}$

Nesse sentido, ao ser perguntando sobre conceitos complexos, Confúcio era vago em defini-los, justamente para não acoplar sentidos desviantes (Confúcio, Lunyu 9, 1, tradução de Simon Leys). Isso não Ihe parecia incoerente, já que um conceito complexo deveria ser apreendido intimamente, e talvez não pudesse

\footnotetext{
12 No original: "冬, 十一月, 已已, 朔, 宋公及楚人戰于泓, 宋人既成列。".

13 No original: "名不正, 則言不順; 言不順, 則事不成; 事不成, 則禮樂不興; 禮樂不興, 則刑罰不中; 刑罰不中, 則民無 所措手足。故君子名之必可言也, 言之必可行也。君子於其言, 無所荷而已矣".
} 
ser explicado por várias palavras - o que implicava associar vários sentidos, caindo no erro de multiplicar analogias incompletas (VANDERMEERSCH 1993; LEVI 1993).

Para a escrita da história e do pensamento chinês, esse passo foi fundamental. Todos os autores após Confúcio consultaram seus escritos, de modo a afirmá-los ou refutá-los. Confúcio conseguira construir um alicerce literário do qual ninguém, com a pretensão de sábio, poderia escapar ou ignorar. O principal, contudo, é que ele consolidou a ideia de se expressar por meio de analogias, tornando o exercício do pensar numa apreciação estética, no qual as imagens devem ser construídas ou desconstruídas para se alcançar um sentido (SCHABERG 2001). Após Confúcio, o debate das ideias tornar-se-ia um criativo e arguto confronto de analogias, favorecendo, por vezes, a construção de belíssimas imagens narrativas. Isso teria um profundo impacto na apreciação da História pelos antigos chineses. As imagens do passado seriam o ponto de partida para decisões políticas, revisões jurídicas e avaliações estratégicas, permanecendo no imaginário como uma fonte infindável de exemplos.

\section{A revisão dos Legistas}

Era esse o ponto, justamente, que dificultava a implantação de uma nova ordem ideológica. Para os legistas, no geral, a instauração de um novo governo passava pelo necessário reforço das leis, da ordem e da centralização do poder. Para autores como Shen Buhai 申不害 (?-337) ou Shang Yang 商鞅 (-390-338) era possível encontrar exemplos, no passado, de governantes que conseguiram fazê-lo (Shang Yang, Shang Junshu 商君書, cap.9 "Cuofa" 錯法). No entanto, dois pontos básicos expunham a fragilidade de seus pontos de vista: o primeiro, de que eles recorriam às histórias recolhidas por Confúcio para delas extraírem uma interpretação própria; e que essa interpretação fatalmente culminava com a afirmação do discurso Confucionista, já que esses mesmos soberanos do passado, quer estivessem tentando algumas práticas tidas como "legistas", foram esporádicos e nem sempre bem sucedidos, levando a intelectualidade chinesa a duvidar da capacidade legista de impor seus pontos de vista.

Foi Hanfeizi 韓非子 (-280-233) que conseguiu, no nível do discurso, resolver o problema da analogia com o passado na escrita histórica. Hanfeizi não negava o procedimento analógico, mas deslocava o problema do sentido para o problema do tempo. Certos contextos apontavam para determinadas tendências ou procedimentos, que não necessariamente se repetiriam. Seu objetivo, na verdade, era abolir a história e o passado chinês, construindo uma nova história para a dinastia que apoiava, os Qin 秦朝 (cuja consolidação se daria, finalmente em -221). Ele propunha que a solução dos problemas chineses somente se daria por uma nova forma de ordenação cósmica, expressa pela construção de leis que indicassem, precisamente, os atributos, espaços e funções de cada elemento no mundo (Hanfeizi, Hanfeizi 韓非子, cap. 5 "Zhudao" 主道. Ver também PINES 2013, p. 67-86; GALVANI 2013, p. 87-107). Desse modo, os Legistas esperavam levar ao máximo a prática da "Retificação dos Nomes", de que se apropriaram do Confucionismo, estabelecendo um novo padrão de linguagem 
e de expressões de sentido (NORDEN 2013, p. 135-147). Nesse âmbito, teria surgido o primeiro dicionário chinês conhecido, o Erya 爾雅 (O Sentido Correto), buscando regular as palavras e seus significados. ${ }^{14}$

Para inaugurar a nova ordem, pois, era necessário desligar-se do passado, representado pela concepção tradicional dos Confucionistas. Nessa pequena história, que iremos analisar, Hanfeizi usa de uma analogia para exemplificar, justamente, a condição de obsolescência do passado:

$\mathrm{Na}$ antiguidade, quando os homens eram uns poucos e as criaturas selvagens abundavam, apareceu um sábio com alguns pedaços de madeira e armou algumas construções, que serviram para as pessoas se guarnecerem dos pássaros, bestas, insetos e serpentes que os atormentavam. As pessoas estavam tão felizes que o nomearam o rei do mundo, chamando-Ihe de "o grande construtor". Naquela época as pessoas comiam frutas, verduras, ostras e mexilhões. Mas os alimentos que armazenavam apodreciam logo e muitos ficavam doentes, morrendo. Então um sábio, juntando madeira, fez fogo e cozinhou os alimentos, e a partir daí menos pessoas ficaram doentes. Este sábio foi reverenciado como o homem do fogo.

$\mathrm{Na}$ época das grandes inundações, que arrasavam com populações inteiras, Cun e Xia fizeram os canais que desviaram as águas e assim evitaram terríveis calamidades. Não faz muito, alguns reis cruéis foram destituídos por Tang e Zhou.

Agora vejam: se construíssemos cercas de madeira, ou tivéssemos feito fogo na época das inundações, isso teria sido completamente ridículo. Se alguém sugerisse fazer canais para evitar as atrocidades dos reis violentos, também teriam sido inúteis. Os sábios, na realidade, não tomam os sucessos do passado e tentam aplicá-los nos dias de hoje; o que fazem é analisar as necessidades atuais e atuar de modo apropriado. Havia um granjeiro em Zhou que arava terra, e em seu campo havia um toco de árvore caído. Um dia, um coelho saiu correndo do mato e se chocou contra o tronco, quebrando o pescoço. Ao vê-lo, o granjeiro deixou o arado e se sentou no tronco, esperando que outro coelho fizesse o mesmo. Só que nenhum outro coelho bateu no tronco, no inverno ele não teve o que comer porque descuidou de suas tarefas e terminou sendo motivo de piadas para os vizinhos. Por isso eu digo: todos aqueles que se valem das regras do passado para governar nos dias de hoje, podem ser chamados com justiça de "Vigilantes do tronco" (Hanfeizi, Hanfeizi cap. 49, tradução de Lin Yutang). ${ }^{15}$

Apesar de construir uma imagem extremamente simples para exemplificar sua ideia, não podemos duvidar que Hanfeizi estava extremamente ciente de como decompor analogias históricas, e alterar suas formas e sentidos. Sua pretensão era mostrar que os exemplos do passado constituíam anacronismos, e seriam incapazes de sugerir ou indicar respostas adequadas ao tempo presente. Esse

\footnotetext{
${ }^{14} \mathrm{~A}$ indicação é de que o livro seria anterior, situado em algum momento entre o século -6 e -3 . Todavia, é a Dinastia Qin que promove a primeira grande unificação dos Logogramas chineses, reeditando o Erya com esse fim. Outro dicionário, o Cangjie Pian 倉頍篇 (Compilação de Cangjie) foi coligido por Lisi 李斯 (-280-208), um dos principais ministros de Qin, e cumpria função similar, mas devidamente ajustada aos padrões culturais e políticos de Qin.

${ }^{15}$ No original: "上古之世, 人民少而禽獸眾, 人民不勝禽獸蟲蛇。有聖人作, 搆木為巢以避群害, 而民悅之, 使王天下, 號 曰有巢氏。民食果茂蜯蛤, 腥臊惡臭而傷害腹胃, 民多疾病。有聖人作, 鑽燧取火以化腥臊, 而民說之, 使王天下, 號之曰 燧人民。中古之世，天下大水，而鯀、禹決瀆。近古之世，桀、紂暴亂，而湯、武征伐。今有搆木鑽燧於夏后氏之世者，必 為鯀、禹笑矣; 有決瀆於殷、周之世者, 必為湯、武笑矣。然則今有美堯、舜、湯、武、禹之道於當今之世者, 必為新聖笑 矣。是以聖人不期脩古, 不法常可, 論世之事, 因為之備。宋人有耕田者, 田中有株, 兔走觸株, 折頸而死, 因釋其来而守 株, 冀復得兔, 兔不可復得, 而身為宋國笑。今欲以先王之政, 治當世之民, 皆守株之類也。".
} 
anacronismo era exemplificado pela palavra Contradição (Maodun 矛楯), que aparece pela primeira vez na literatura chinesa em seus escritos, e representa a contraposição de termos conflitantes numa analogia, como se segue nesse pequeno texto:

Na região de Chu viveu um homem que vendia lanças e escudos.

- Meus escudos são tão fortes - vangloriava-se ele - que nada consegue atravessá-los! Minhas lanças são tão afiadas que conseguem perfurar qualquer coisa!

Alguém que vinha passando quis saber:

- E o que acontece se suas lanças batem nos seus escudos?

O homem não soube responder (Hanfeizi, Hanfeizi cap. 36, tradução minha). ${ }^{16}$

Mao 矛 (Lança) e Dun 楯 (Escudo) são opostos complementares neste fragmento. São Ihes atribuídas propriedades que, se testadas, revelarão a falha em um dos dois. Na continuação do texto, ele discorre longamente sobre a impropriedade de usar a sabedoria do passado no presente. Esse tipo de inadequação, aos olhos de Hanfeizi, é que provocaria os erros nos discursos e as falhas nas analogias em relação ao passado. Para uma escrita histórica correta, portanto, os meios deveriam ser adequados ao propósito e ao tempo - mais exatamente, ao seu tempo - único sobre o qual ele possuiria uma referência direta. A história, então, tornar-se-ia sempre uma história do tempo presente, cuja escrita seria renovada toda vez que um novo soberano assumisse o poder.

\section{A escrita histórica em Qin}

Hanfeizi acabou sendo vítima de uma intriga palaciana, que o condenou à morte antes de Qin completar a unificação da China em -221. Contudo, o efeito da influência legista foi nitidamente sentido na escrita histórica. Além das crônicas de Qin, o único manual histórico produzido nessa época foi $A s$ Primaveras e Outonos de Lu (Lushi Chunqiu 呂氏春秋), de autoria de Lubuwei 呂 不韋 (-290-236), ministro e conselheiro do primeiro imperador de Qin. Embora invocasse o nome do clássico confucionista, seu livro é uma coletânea de tratados científicos, astronômicos, discursos, análises do Yijing, entre outros (KNOBLOCK 2000). Sua concepção, portanto, era absolutamente contemporânea à época. Ele preservava conhecimentos de uso prático, e aludia a questões, costumes e práticas correntes. O passado está ali, mas não é dito; o que se reproduz é o saber definido pelo novo poder, pela nova história; o que continua é definido pelo presente, e não pela tradição.

A melhor expressão disso foi a tentativa de Qinshi Huangdi 秦始皇 帝 (o primeiro soberano Qin) de tornar-se o monarca perfeito, sem modelo correspondente ou igual no passado. Yuri Pines (2014, p. 277-301) nos mostra sua tentativa de acabar com todas as analogias possíveis à sua imagem, criando para si mesmo uma figura messiânica, distinta de tudo que já havia acontecido 
no passado. Para isso, ele levou a cabo duas medidas extremas para abolir o passado: a primeira constituiu-se na criação de uma lista de livros proibidos, que foram recolhidos e queimados em -213 (Sima Qian, Shiji, cap. 6, Qinshi Huang Beiji 秦始皇本紀 e cap. 87, Lisi Liezhuan 李斯列傳; ver também SIMA QIAN 1994, p. 74). Foi, provavelmente, a primeira destruição ideológica de livros da história da humanidade. Na lista, estavam todos os livros de outras escolas de pensamento concorrentes aos legistas, bem como os clássicos chineses de História (Shujing e Chunqiu) e da Poesia (Shijing). Quaisquer textos que pudessem expor o passado chinês deveriam ser destruídos. Isso provocou um movimento subversivo de ocultação de livros e bibliotecas. A reação do governo foi violenta: em -210 foi ordenado que quatrocentos e sessenta intelectuais fossem enterrados vivos, por não cumprimento das ordens governamentais (Sima Qian, Shiji, cap. 6, Qinshi Huang Benji 秦始皇本紀). Por fim, de modo que a história fosse escrita por ele próprio, e seu governo se tornasse eterno, o imperador enveredou por uma busca pela imortalidade, que se revelaria posteriormente fatal (Sima Qian, Shiji, cap. 6, Qinshi Huang Benji 秦始皇本紀). Ao mesmo tempo em que mandara construir o seu famoso Mausoléu (ciente, o que é muito provável, de que sua busca poderia não dar certo), Qinshi Huangdi começou a contratar alquimistas que lhe fabricassem poções mágicas para alcançar a perenidade física. Acreditase que um desses remédios tenha sido a causa do envenenamento que o levou à morte (Sima Qian, Shiji, cap. 6, Qinshi Huang Benji 秦始皇本紀).

Todavia, no plano ideológico, ele estava longe de alcançar seus propósitos, 38 em função da resistência da sociedade chinesa em aceitar a abolição do tempo e das tradições. Tais atitudes causaram temor, mas igualmente revolta com o novo regime. Isso implicaria numa crítica severa às concepções defendidas por Hanfeizi, tanto no âmbito político quanto historiográfico.

\section{Desdobramentos pós-Qin}

O desastre causado pela violenta unificação política imposta pela Dinastia Qin não foi suficiente para pôr um "fim" na história chinesa. De fato, após a queda de Qin, os intelectuais chineses defenderam o discurso de que a arrogância e prepotência de seus governantes, ao não aceitarem e nem compreenderem os exemplos contidos na história, é que levaram a dinastia, justamente, ao mesmo fracasso dos imperadores anteriores, como proposto por Jiayi 賈誼 (-201-168) em seu ensaio Os crimes de Qin (Guo Qin 過秦, cap. 3, Guo Qin Xia 過秦下), presente no livro Novos Textos: "Diz um antigo provérbio: "Quem conhece o passado, compreende o futuro". Assim, um educado de qualquer país, que conhece a antiguidade, espalha seu saber pelo mundo e atinge a todas as coisas" (Xinshu 新書, tradução minha). ${ }^{17}$

O caminho estava aberto para uma retomada da escrita histórica nos moldes Confucionistas. A tomada do poder pela Dinastia Han 漢朝 $(-206+221)$ marcou 0 estabelecimento do Confucionismo como doutrina oficial de governo. Cansados da opressão imposta pelos legistas, os chineses receberam de bom grado a

\footnotetext{
17 No original: "鄙諺曰: 前事之不忘, 後之師也。是以君子為國, 觀之上古, 驗之當世, 參之人事。".
} 
possibilidade das escolas filosóficas voltarem a debater. De fato, um aspecto interessante no modo de pensar confucionista era a ampla tolerância com as outras escolas de pensamento, que continuaram a existir e marcar presença na corte, embora - com exceção do Daoísmo - com uma influência relativamente reduzida (CHENG 1985).

Nesse contexto, um processo de síntese desenrolou-se entre essas linhas de pensamento tradicionais. O período Han marcou um fértil momento de diálogo e troca intelectual, promovendo contribuições filosóficas mútuas (BUENO 2014), que ocorreram em função da estabilidade do poder e do ambiente livre e propício ao debate. Dong Zhongshu 董仲舒 (-179-104) foi um dos autores mais destacados desse período, por propor uma inovadora teoria de história natural. Dong defendia, por meio do sistema de correlação, que o curso da história política chinesa, bem como sua organização social, estavam vinculados aos movimentos da natureza, organizado no Ciclo dos cinco movimentos (Wuxing 五 行). A compreensão do papel do imperador, das classes sociais, dos movimentos culturais, tudo estaria conectado com o processo de reprodução da natureza, o que poderia ser identificado pela análise da história (QUEEN 1996). Daí sua obra constituir-se de um amplo comentário as Primaveras e Outunos (Chunqiu), intitulado Gemas Preciosas das Primaveras e Outonos (Chunqiu Fanlu 春秋繁 露). Em sua visão, a análise das antigas passagens de Confúcio nos revelaria a ênfase dos agentes naturais (água, fogo, metal, terra e madeira) na ação humana, num contínuo movimento de interação natureza-humanidade.

A obra de Dong foi basilar para o pensamento chinês por duas razões; primeira, por inter-relacionar diretamente o ser humano com as fases da natureza e da matéria, questão crucial para vários campos do pensamento chinês, como é o caso da Medicina Tradicional Chinesa. As teorias encontradas em sua obra eram bem anteriores à sua época, mas Dong foi capaz de criar uma nova teoria aglutinadora eficaz, cujo sistema foi reconhecido e debatido por todas as gerações posteriores. Novamente, ele invocou o pensamento correlato, presente no íntimo do imaginário chinês, e estabeleceu uma série de analogias capazes de 'explicar' os fenômenos sociais. Com isso, ele re-estabeleceu um segundo ponto fundamental no pensamento chinês, defendido anteriormente por Confúcio: o papel fundamental da compreensão da história para a continuidade da cultura e do sistema político [o império] cujas raízes seriam essencialmente naturais, ou de Tudo-abaixo-do-Céu (天下 Tianxia). Suas teorias não apenas reforçam a entidade imperial, mas também, ressaltam que a base para a compreensão e manutenção da sociedade consiste num estudo aprofundado da história e de seus movimentos.

Mas foi Sima Qian 司馬遷 (-145-90), aluno de Dong Zhongshu, que seria considerado o principal historiador do período Han - e talvez, da civilização chinesa -, por redigir uma extensa coleção chamada Registros Históricos (Shiji 史 記), inaugurando a longa série de histórias oficias do império chinês (publicadas até 1911). Sima Qian era historiador e astrólogo da Corte, tendo herdado o cargo do pai. Sua proposta consistia em aprofundar o ponto de vista de Confúcio, investindo na escrita de uma ampla obra cujas seções temáticas re-interpretavam 
os antigos modelos de redação histórica. Obra basilar da historiografia chinesa, ela retomaria o uso das analogias com o passado, que estão presentes num vasto conjunto de biografias históricas que compõem sua obra. O livro é dividido da seguinte maneira: a seção Biao 表 organizava, em dez capítulos, a cronologia dos tempos antigos; as seções Benji 本紀, Shijia 世家 e Liezhuan 列傳 compõem cento e doze capítulos de biografias diversas; por fim, a seção Shū 書 é composta de oito tratados sobre temas variados (como música, calendário ou astronomia, entre outros). Sima Qian reconfigurou em sua escrita, portanto, a estrutura do Chunqiu nas cronologias e nos tratados; e explica-lhes os sentidos nas biografias, inspiradas tanto nos comentários do Chunqiu quanto na estrutura de discurso do Shujing (HARDY 1999). Essa estrutura seria fundamental na redação histórica chinesa, consolidando um formato estilístico no uso das analogias que permaneceria continuamente durante toda a Era imperial.

\section{Conclusão}

De fato, pois, os historiadores chineses estavam convictos da importância do uso das analogias com o passado na escrita histórica. Retomado o seu uso, ela voltaria a ser um conceito (e um recurso) fundamental na estrutura da história chinesa, tornando-se, doravante, o ponto de partida de qualquer discussão histórica, filosófica ou política. Os chineses não conseguiram (ou mesmo, não quiseram) se desvincular da associação entre ideias e imagens, tão cara à sua escrita e aos seus sistemas de pensamento. No mais, o trabalho historiográfico sempre foi de interesse majoritário entre os confucionistas (e ocasionalmente entre os legistas, como no caso de Hanfeizi), cuja crença na redenção sapiencial pelo conhecimento histórico e cultural era um pilar de sua doutrina. Desde Confúcio, a necessidade de se inspirar no passado tornou-se parte de seu método, pelo qual se analisava as semelhanças ou as diferenças com o passado, ou ainda, a ocorrência de precedentes. Tal pensamento dominaria a mentalidade histórica Chinesa, atravessando os séculos vindouros (ON-CHO 2005), e influenciando, ainda hoje, sua concepção de Civilização e identidade cultural.

\section{Referências bibliográficas}

ALLETON, Viviane. Escrita Chinesa. Porto Alegre: L\&PM, 2010.

BUENO, André. O Pensamento chinês durante a Dinastia Han. In BUENO, André e NETO, José (orgs.) Antigas Leituras: visões da China Antiga. União da Vitória: UNESPAR/UPE, p.178-200, 2014. Disponível em: http:// orientalismo.blogspot.com.br/2014/11/livro-antigas-leituras-visoes-dachina.html. Acesso em: 24 fev. 2015.

CHENG, Anne. Étude sur le confucianisme han: I"élaboration d"une tradition exégétique sur les classiques. Paris: Collège de France et Institut des Hautes Études Chinoises, 1985.

CONFÚCIO (孔夫子). Os Analectos. Tradução de Simon Leys. São Paulo: Martins Fontes, 2009. 
. Chunqiu 春秋. Disponível em: http://ctext.org/chun-qiu-zuo-zhuan. Acesso em: 24 fev. 2015.

. Lunyu 論語. Disponível em: http://ctext.org/analects. Acesso em: 24 fev. 2015.

Shangshu 尚書 (Shujing 書經). Disponível em: http://ctext.org/shangshu. Acesso em: 24 fev. 2015.

GALVANY, Albert. Beyond the Rule of Rules: The Foundations of Sovereign Power in the Han Feizi. In: GOLDIN, Paul R. Dao Companion to the Philosophy of Han Fei. New York: Springer, 2013.

HANFEIZI (韓非子). Livro de Hanfeizi. Tradução de Lin Yutang. In: BUENO, André. Cem textos de História chinesa. União da Vitória: UNESPAR/ UPE, 2009. Disponível em: http://chinologia.blogspot.com.br/2009/08/ historia.html. Acesso em: 24 fev. 2015.

. Hanfeizi 韓非子. Disponível em: http://ctext.org/hanfeizi. Acesso em: 24 fev. 2015.

HARDY, Grant. The worlds of bamboo and bronze: Sima Qian's conquest of history. Columbia: Columbia University Press, 1999.

JIAYI (賈誼). Xinshu 新書. Disponível em: http://ctext.org/xin-xu. Acesso em: 24 fev. 2015.

KNOBLOCK, John. The Annals of Lü Buwei: a Complete Translation and Study. Stanford: Stanford University Press, 2000.

LEVI, Jean. Quelques aspects de la rectification des noms dans la pensée et la pratique politiques de la Chine ancienne. Extrême-Orient, ExtrêmeOccident. v.15, n. 15, p. 23-53, 1993.

LIUXIE (刘妿思). El corazón de la literatura y el cincelado de dragones. Tradução de Alicia Riqueta. Granada: Comares, 1995.

. Wenxin Diaolong 文心雕龍. Disponível em: http://ctext.org/wenxindiaolong. Acesso em: 24 fev. 2015.

$\mathrm{ON}-\mathrm{CHO}, \mathrm{Ng}$; WANG, Edward. Mirroring the past: the writing and use of history in imperial China. Honolulu: University of Hawai Press, 2005.

PINES, Yuri. O Messianismo do Primeiro Imperador. In: BUENO, André; NETO, José (orgs.). Antigas Leituras: visões da China Antiga. União da Vitória: UNESPAR/UPE, 2014, p. 277-301. Disponível em: http://orientalismo. blogspot.com.br/2014/11/livro-antigas-leituras-visoes-da-china.html. Acesso em: 24 fev. 2015.

. Submerged by Absolute Power: The Ruler"s Predicament in the Han Feizi. In: GOLDIN, Paul R. Dao Companion to the Philosophy of Han Fei. New York: Springer, 2013. 
QUEEN, Sarah. From chronicle to Canon: the hermeneutics of the Spring and Autumn, according to Tung Chung-shu. Cambridge: Cambridge University Press, 1996.

SCHABERG, David. A Patterned Past: form and Thought in Early Chinese Historiography. Harvard: Harvard University Press, 2001.

SHANG YANG (商鞅). Shang Junshu 商君書. Disponível em: http://ctext.org/ shang-jun-shu. Acesso em: 24 fev. 2015.

SIMA QIAN (司馬遷). Records of the Grand Historian: Qin Dynasty. Tradução de Burton Watson. Columbia: Columbia University Press, 1993.

.The first Emperor: selections from the Record of Grand Historian. Tradução de Raymond Dawson. Oxford: Oxford University Press, 1994.

. Shiji 史記. Disponível em: http://ctext.org/shiji. Acesso em: 24 fev. 2015.

VAN NORDEN, Bryan. Han Fei and Confucianism: Toward a Synthesis. In: GOLDIN, Paul R. Dao Companion to the Philosophy of Han Fei. New York: Springer, 2013.

VANDERMEERSCH, Leon. Rectification des noms et langue graphique chinoises Extrême-Orient, Extrême-Occident. v. 15, n. 15, p. 11-21, 1993.

VOLKOV, Alexei. Analogical Reasoning in Ancient China: some examples. Extrême-Orient, Extrême-Occident. v. 14, n. 14, p. 15-48, 1992.

YATES, Robin. Introduction: The Empire of the Scribes. In: PINES, Yuri et al. (orgs.). Birth of an Empire: The State of Qin Revisited. Berkeley: California University Press, 2014.

ZUOQIUMING (左丘明). Zuozhuan 左傳. Disponível em: http://ctext.org/chun-qiuzuo-zhuan. Acesso em: 24 fev. 2015. 